\title{
VISUALISASI PEMBELAJARAN TEKUK PADA KOLOM DENGAN BANTUAN SOFTWARE BERBASIS PERHITUNGAN NUMERIK
}

\author{
Yosafat Aji Pranata, Anang Kristianto \\ Dosen Tetap, Jurusan Teknik Sipil, Fakultas Teknik, Universitas Kristen Maranatha \\ Jalan Prof. drg. Suria Sumantri MPH., No. 65, Bandung, 40164 \\ e-mail: yosafat.ap@eng.maranatha.edu, anang.kristianto@eng.maranatha.edu
}

\begin{abstract}
ABSTRAK
Proses pembelajaran merupakan suatu proses komunikasi antara dosen dengan mahasiswa, yaitu bagaimana materi disampaikan, kurikulum sebagai rangkaian materi kuliah, serta hasil proses pembelajaran. Ketiga komponen tersebut saling terkait. Dalam prakteknya, banyak terjadi kendala ketika mahasiswa berhadapan dengan materi kuliah yang sulit untuk dibayangkan, bahkan untuk materi yang secara matematis dapat dituliskan dengan sederhana. Kondisi ini berhubungan dengan gaya belajar mahasiswa. Hasil penelitian yang dilakukan terhadap mahasiswa teknik pada beberapa perguruan tinggi menunjukkan bahwa gaya belajar visual leaners ternyata lebih dominan daripada active leaners dan sensing leaners. Mahasiswa dengan gaya belajar active-sensing-visual leaners memiliki kecenderungan belajar melalui metode praktis problem-solving, penggunaan banyak gambar, grafik atau sketsa sederhana serta aktivitas kelompok dimana mahasiswa diberi kesempatan untuk bertukar pikiran. Dalam penulisan ini disampaikan masukan untuk pembelajaran tekuk pada kolom dengan visualisasi menggunakan alat bantu software komputer. Beberapa manfaat penggunaan alat bantu ini adalah yang pertama, mahasiswa dapat memahami proses mulai dari dasar teori, penggunaan rumus, latihan soal serta hasil perhitungan dapat terdokumentasi dengan baik. Kedua, dengan bantuan flowchart yang berguna untuk menjelaskan urutan suatu proses pelaksanaan yang mempunyai banyak kondisi pilihan atau percabangan. Ketiga, mahasiswa dapat melakukan berbagai variasi simulasi sederhana untuk berbagai kondisi bentuk, dimensi serta ukuran kolom.
\end{abstract}

Kata kunci: Gaya belajar, Visualisasi, Tekuk, Kolom.

\section{PENDAHULUAN}

Proses pembelajaran bukan hanya suatu proses komunikasi bagaimana materi disampaikan kepada mahasiswa, akan tapi terdapat dua komponen penting lain yang saling terkait, yaitu kurikulum sebagai rangkaian materi kuliah serta hasil proses pembelajaran.

Pada kenyataannya, terdapat kecenderungan bahwa materi yang telah disusun dengan baik tidak dapat disampaikan secara efektif. Hal ini mempengaruhi hasil yang diharapkan. Dalam konteks ini, mekanika bahan sebagai salah satu mata kuliah utama dalam pendidikan teknik sipil di Indonesia mengalami permasalahan yang sama, yaitu menurunnya hasil belajar mahasiswa.

Memberikan pemahaman kepada mahasiswa ternyata tidak mudah. Dari segi materi kuliah, hal ini dipengaruhi oleh beberapa hal, yaitu antara lain dasar teori, asumsi dan perhitungan matematis, serta visualisasi dalam bentuk grafik atau gambar. 
Sebagai gambaran, pada penulisan ini dipaparkan hasil penelitian yang telah dilakukan oleh Kristianto dan MSDU [Kristianto, 2004] terhadap mahasiswa Jurusan Teknik Sipil Universitas Kristen Maranatha. Hasil penelitian menunjukkan kecenderungan gaya belajar adalah active-sensing leaners (41,38\%) dan visual leaners (68,97\%).

Kemudian sebagai perbandingan, dilakukan suatu studi literatur terhadap hasil penelitian yang dilakukan oleh Felder [Felder, 2005] terhadap mahasiswa di beberapa universitas terkemuka di Amerika. Hasil penelitian terhadap mahasiswa Iowa State University menyatakan bahwa $63 \%$ mahasiswa adalah active leaners, $67 \%$ sensing leaners, dan $85 \%$ visual leaners. Penelitian terhadap mahasiswa Michigan Tech. menunjukkan bahwa $56 \%$ active leaners, $63 \%$ sensing leaners, dan 74\% visual leaners. Secara umum hasil penelitian Felder menunjukkan bahwa $64 \%$ active leaners, $63 \%$ sensing leaners, dan $82 \%$ visual leaners.

Kondisi tersebut setidaknya bisa memberikan gambaran yang cukup umum bahwa mahasiswa teknik memiliki kecenderungan gaya belajar yang hampir sama di beberapa perguruan tinggi.

Mahasiswa dengan gaya belajar active-sensing-visual leaners memiliki kecenderungan belajar melalui metode praktis problem-solving, penggunaan banyak gambar, grafik atau sketsa sederhana serta aktivitas kelompok dimana mereka diberi kesempatan untuk bertukar pikiran.

Salah satu kendala pemahaman terhadap materi adalah ketika mahasiswa berhadapan dengan materi mekanika bahan yang sulit untuk dibayangkan, bahkan untuk materi yang secara matematis dapat dituliskan dengan sederhana. Salah satu materi dasar yang diberikan adalah tekuk pada kolom. Memberikan pemahaman kepada mahasiswa mengenai tekuk pada kolom, penggunaan dan penempatan pengaku ternyata tidak mudah. Dalam penulisan ini disampaikan masukan untuk pembelajaran tekuk pada kolom dengan visualisasi menggunakan alat bantu software komputer.

Tujuan dari penulisan ini adalah agar mahasiswa menjadi lebih fokus pada proses pembelajaran tekuk pada kolom tanpa mengabaikan pemahaman dasar teori. Selain itu untuk membuat mata kuliah tekuk pada kolom menjadi lebih menarik dan meningkatkan kemampuan mahasiswa pada pemanfaatan komputer.

Penulisan menggunakan ruang lingkup batasan materi tekuk pada kolom. Visualisasi pembelajaran dilakukan dengan bantuan software komputer yang dikembangkan secara mandiri dengan mengunakan bahasa pemrograman DELPHI, yaitu suatu bahasa 
pemrograman berbasis perhitungan numerik, yang dapat juga melakukan visualisasi kedalam bentuk grafik atau gambar.

\section{GAYA DAN CARA BELAJAR MAHASISWA}

Kegagalan mahasiswa dalam mengikuti pembelajaran mekanika rekayasa, sebagaimana biasa dikeluhkan dosen, condong hanya ditinjau dari sisi mahasiswa saja, yaitu sebagai kekurangan mahasiswa. Kekurangan yang dikontribusikan oleh dosen jarang atau malah tidak ditinjau, sehingga tidak diperhitungkan dalam program perbaikan yang dikontruksi untuk mengatasi masalah gagal komunikasi yang timbul [Besari, 2004].

Gaya belajar membahas tentang perbedaan cara individu untuk lebih efektif mempelajari suatu konsep. Selain gaya belajar, setiap mahasiswa juga memiliki cara belajar yang berbeda. Cara belajar merupakan suatu perbedaan cara yang dilakukan untuk memahami informasi secara optimal [Kristianto, 2004].

Salah satu upaya agar proses pembelajaran berhasil secara optimal adalah dosen berusaha untuk menyampaikan materi dengan baik dan kompeten. Salah satunya adalah mengajar dengan memahami gaya dan cara belajar mahasiswa.

Hasil penelitian seperti yang telah disampaikan pada pendahuluan diatas dapat memberikan informasi yang bermanfaat secara khusus pada kasus ini adalah matakuliah mekanika rekayasa pada mahasiswa teknik.

\section{TINJAUAN LITERATUR}

Kolom merupakan elemen struktur yang sangat banyak digunakan. Secara umum, kolom dibagi menjadi dua tipe, yaitu kolom pendek dan kolom panjang. Kolom pendek adalah tipe kolom yang kegagalannya berupa kegagalan material (ditentukan oleh kekuatan material), sedangkan kolom panjang adalah tipe kolom yang kegagalannya ditentukan oleh tekuk (buckling), jadi kegagalan karena ketidakstabilan [Schodek, 1999].

Beban tekuk kritis adalah beban maksimum yang dapat dipikul kolom. Peningkatan kecil dari beban ini akan meningkatkan lendutan secara signifikan, yang memungkinkan terjadinya kegagalan stabilitas [Lwin, 2001].

Beban tekuk kritis untuk kolom panjang yang digunakan dalam penulisan ini menggunakan persamaan Euler. Modifikasi persamaan Euler bergantung pada panjang efektif kolom. Rasio panjang efektif merupakan rasio panjang efektif dari idealisasi perletakan ujung kolom terhadap panjang aktual kolom untuk berbagai kondisi perletakan ujung. 


$$
P_{c r}=\frac{\pi^{2} \cdot E \cdot I}{(K \cdot L)^{2}}
$$

dimana :

$P_{c r} \quad=$ Beban tekuk kritis.

$E \quad=$ Modulus elastisitas.

$I \quad=$ Momen inersia penampang.

$K \quad=$ Rasio panjang efektif kolom.

$L \quad=$ Panjang kolom.

Beberapa ilustrasi untuk menggambarkan tekuk pada kolom dapat dilihat pada Gambar 1 dan Gambar 2.

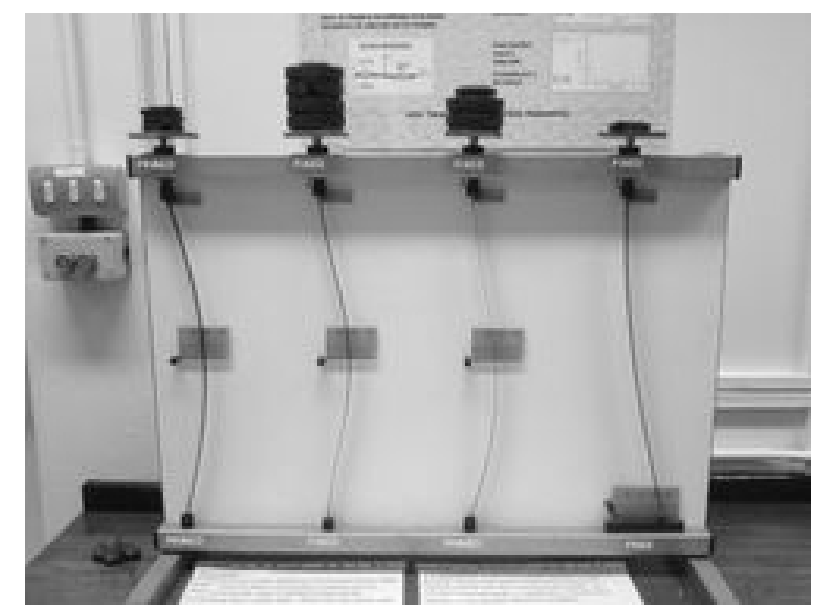

Gambar 1. Beberapa model tekuk pada kolom [Sumber : http://www.wikipedia.com].

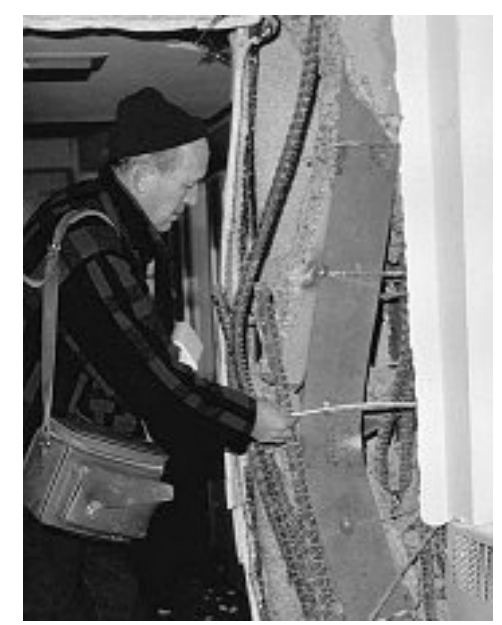

Gambar 2. Kegagalan kolom karena tekuk [Sumber : http://www.arch.virginia.edu]. 


\section{VISUALISASI PEMBELAJARAN DENGAN SOFTWARE}

Pada saat ini terdapat banyak software untuk pemodelan dan perhitungan tekuk pada kolom. Sebagai contoh adalah software ALADDIN dan MDSOLIDS.

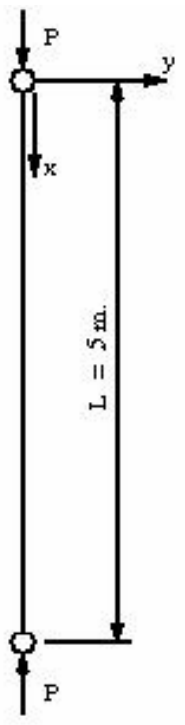

GEOMETRY OF ELASTIC ROD

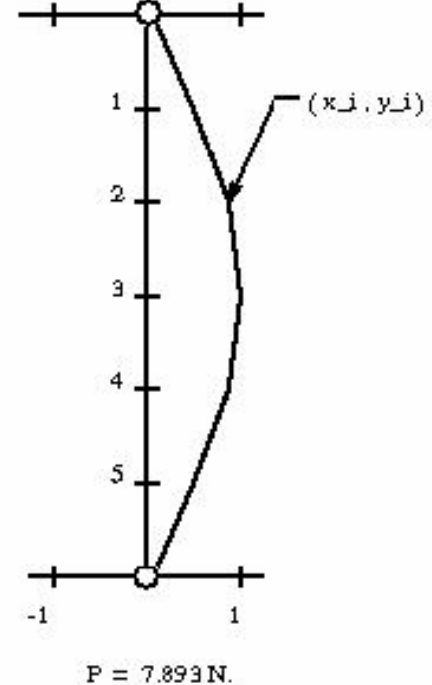

BUCKLING MODE 1

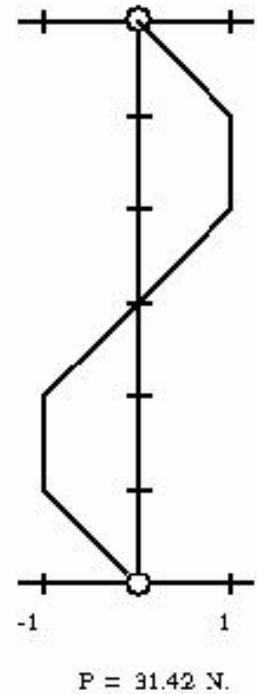

BUCKLING MODE 2

Gambar 3. Perhitungan beban tekuk Euler dengan software ALADDIN.

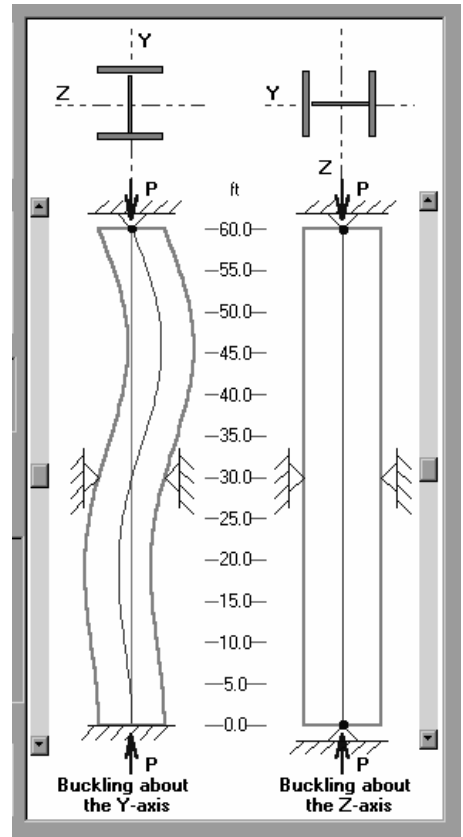

Gambar 4. Visualisasi tekuk pada kolom dengan software MDSOLIDS.

Dalam penulisan ini juga disampaikan suatu software sederhana namun cukup interaktif untuk visualisasi materi tekuk pada kolom, yang dikembangkan secara mandiri 
dengan bahasa pemrograman DELPHI. Informasi lebih lanjut mengenai software ini dapat di-download pada website http://yosafat.ap.tripod.com.

Software-software yang ada tersebut sangat efektif untuk digunakan dalam perhitungan dengan berbagai variasi data masukan dan proses perhitungannya pun sangat cepat. Namun apabila terjebak pada mitos bahwa software selalu benar dan tidak mengetahui serta memahami parameter-parameter yang digunakan sebagai data masukan (input), maka hal ini bisa berakibat fatal, karena bisa menghasilkan suatu interpretasi hasil yang tidak tepat.
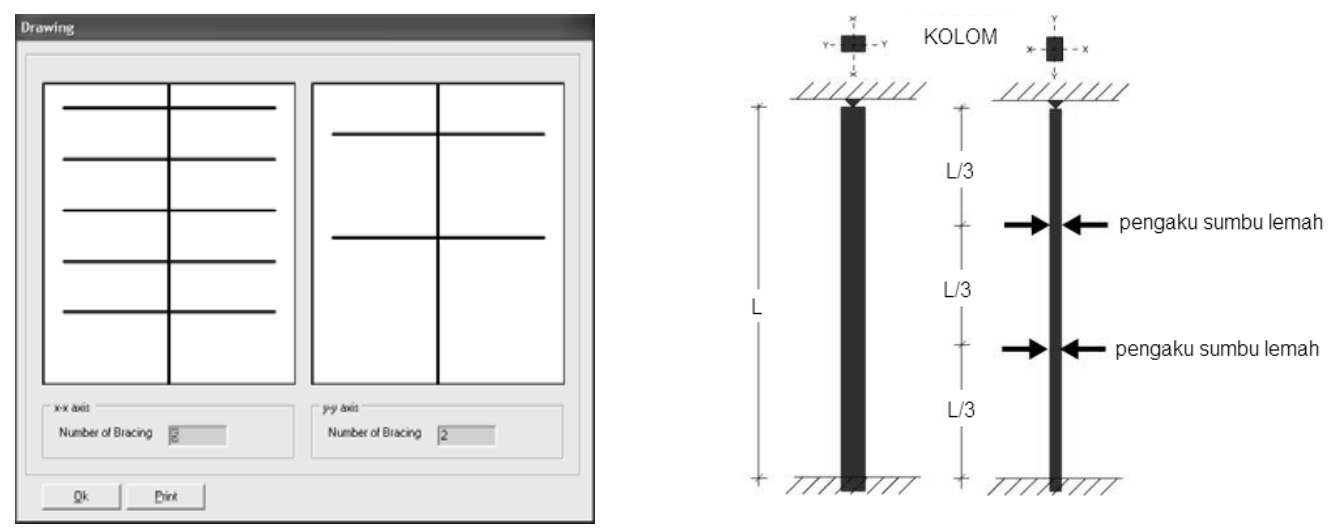

Gambar 5. Kolom dengan variasi penempatan pengaku.
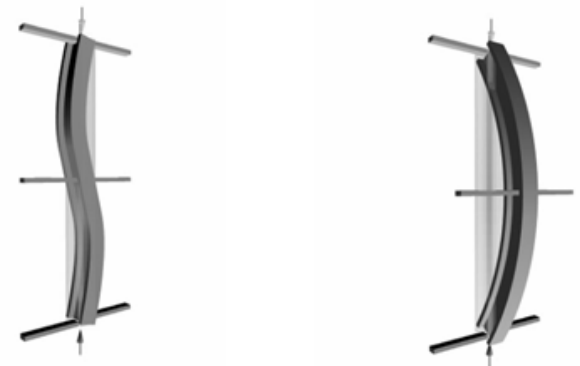

(a). Arah sumbu lemah. (b). Arah sumbu kuat.

\section{Gambar 6. Tekuk pada kolom dengan pengaku.}

\subsection{Algoritma dan Flowchart}

Algoritma merupakan suatu strategi penyelesaian suatu masalah secara detail sehingga dapat dilakukan proses oleh komputer secara efisien dan tepat. Agar dapat diproses oleh komputer, maka algoritma diterjemahkan terlebih dahulu ke dalam bahasa pemrograman. 
Flowchart atau bagan alir diperlukan untuk memudahkan menjelaskan suatu proses yang rumit bila diuraikan dengan kata-kata. Flowchart sangat berguna untuk menjelaskan urutan suatu proses pelaksanaan yang mempunyai banyak kondisi pilihan atau percabangan.

Bagan alir digunakan untuk membuat software. Dalam penulisan ini bagan alir proses perhitungan secara garis besar seperti terlihat pada Gambar 7. Secara umum, terlebih dahulu diperiksa rasio kelangsingan, dan menghitung beban tekuk kritis sesuai persamaan Euler (persamaan 1). Kemudian visualisasi dilakukan sebagai contoh perlu atau tidaknya penggunaan pengaku. Beberapa simulasi sederhana dapat dilakukan dengan variasi bentuk, dimensi dan ukuran penampang kolom, serta penempatan pengaku.

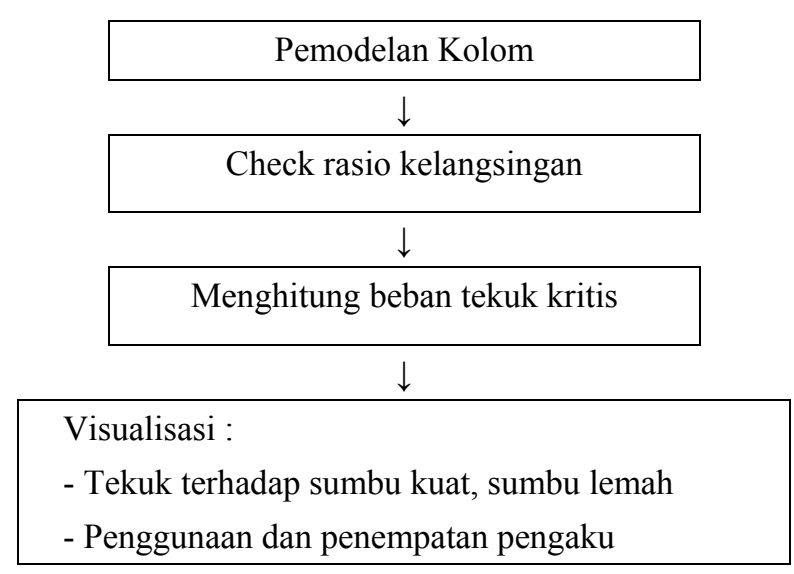

Gambar 7. Flowchart yang digunakan dalam studi.

Perhitungan rasio kelangsingan menggunakan persamaan 2 dan persamaan 3.

$$
\begin{aligned}
& \frac{K . L}{r} \leq \text { rasio ijin } \\
& r=\sqrt{\frac{I}{A}}
\end{aligned}
$$

dimana $r$ adalah jari-jari girasi penampang kolom dan $A$ adalah luas penampang kolom.

\subsection{Software Interaktif Berbasis Perhitungan Numerik}

Beberapa manfaat menggunakan bahasa pemrograman berbasis perhitungan numerik adalah dapat menentukan sendiri data-data masukan yang akan digunakan untuk rangkaian perhitungan. Persamaan-persamaan yang akan digunakan dalam perhitungan pun dapat ditentukan sendiri sesuai keperluan. Kemudian hasil perhitungan yang akan divisualisasikan dalam bentuk gambar atau diagram dapat ditampilkan dengan baik, bahkan untuk model 3 dimensi.

Beberapa manfaat tersebut dapat digunakan untuk menampilkan suatu pemodelan tekuk pada kolom secara interaktif. Namun pada akhirnya, tetap diperlukan dasar teori dan 
asumsi pemahaman yang benar terlebih dahulu, karena hal ini sangat penting agar interpretasi hasil juga menjadi benar.

\subsection{Studi kasus dan Pembahasan}

Beberapa variasi perletakan ujung-ujung kolom untuk menghitung panjang efektif kolom menggunakan asumsi seperti terlihat pada Gambar 8.

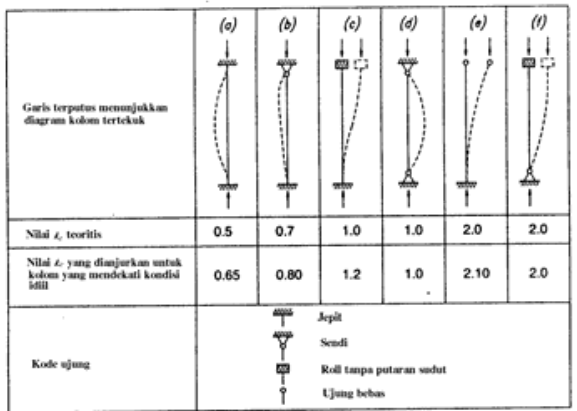

Gambar 8. Nilai ( $K_{e}$ ) untuk kolom dengan berbagai jenis kekangan ujung.

Penulisan ini menggunakan contoh studi kasus kolom persegi $150 \mathrm{~mm} \times 300 \mathrm{~mm}$, dengan tinggi 10 meter, dengan model perletakan jepit pada ujung bawah dan sendi pada ujung atas. Sebagai asumsi digunakan batasan rasio kelangsingan ijin sebesar 175.

Hasil perhitungan cek rasio kelangsingan menunjukkan bahwa baik pada sumbu kuat maupun sumbu lemah tidak memenuhi persyaratan rasio kelangsingan ijin (rasio kelangsingan masing-masing 461,88 dan 230,94). Maka sebagai penyelesaian, dalam penulisan ini mengambil solusi digunakan pengaku. Agar memenuhi persyaratan kelangsingan, maka digunakan dua buah pengaku pada arah sumbu lemah dan satu buah pengaku pada arah sumbu kuat.

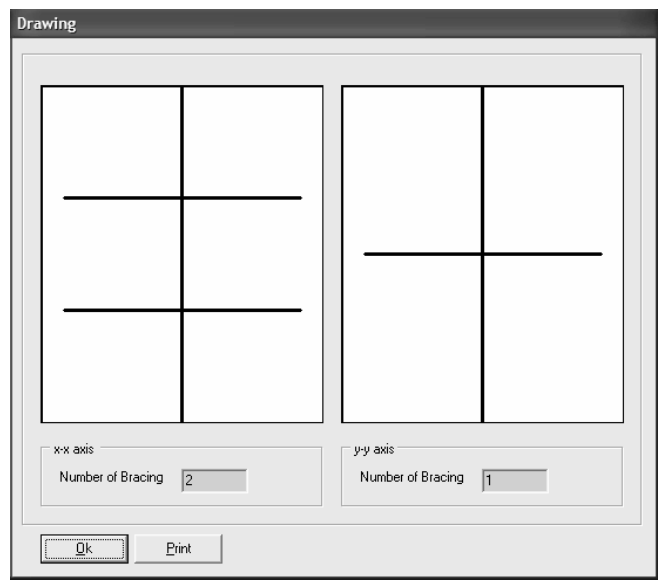

Gambar 9. Penggunaan pengaku. 
Sebagai tambahan untuk melengkapi visualisasi tersebut, dalam program ini juga disertakan reports berupa urutan langkah demi langkah perhitungan, sehingga alur perhitungan dapat dipahami dengan baik.

\section{KESIMPULAN}

Kesimpulan dan beberapa manfaat penggunaan alat bantu ini adalah :

1. Mahasiswa dapat memahami proses mulai dari dasar teori, penggunaan rumus, latihan soal serta hasil perhitungan dapat terdokumentasi dengan baik.

2. Dengan bantuan flowchart, sangat berguna untuk menjelaskan urutan suatu proses pelaksanaan yang mempunyai banyak kondisi pilihan atau percabangan.

3. Mahasiswa dapat melakukan berbagai variasi simulasi sederhana untuk berbagai kondisi bentuk, dimensi serta ukuran kolom.

Materi dalam penulisan ini dipresentasikan pada "Lokakarya Pembelajaran Mekanika Teknik, Konstruksi Beton, dan Konstruksi Baja”, di Universitas Udayana, Bali, pada tanggal 26-27 Juli 2006.

\section{DAFTAR PUSTAKA}

1. Besari, M.S. (2004), Pembelajaran Ilmu Mekanika Rekayasa, Seminar dan Workshop Nasional Mekanika Rekayasa Teknik Sipil, 7-8 Oktober 2004, Universitas Atma Jaya Yogyakarta, Yogyakarta.

2. Borland (2001), DELPHI User Guide, Borland Software Corporation.

3. Felder, R.M., Brent, R. (2005), Understanding Student Differences, Journal of Engineering Education, 94 (1), 57-72, January 2005.

4. Hibbeler, R.C. (1997), Mechanics of Materials $3^{\text {rd }}$ Edition, Prentice Hall, Inc.

5. Kristianto, A. (2004), Mengajar Mekanika Rekayasa Dengan Memahami Gaya Dan Cara Belajar Mahasiswa, Seminar dan Workshop Nasional Mekanika Rekayasa Teknik Sipil, 7-8 Oktober 2004, Universitas Atma Jaya Yogyakarta, Yogyakarta.

6. Lwin, M.M., Lee, C.S., Lee, J.J. (2001), Civil Engineering PE Exam Depth Guide, McGraw-Hill.

7. Schodek, D.L., (1999), Struktur, Edisi kedua, Penerbit Erlangga, Jakarta.

8. url: http://instruct1.cit.cornel.edu

9. url: http://msumusik.mursuky.edu/mdsolids 
10. url: http://www.arch.virginia.edu

11. url: http://www.isr.umd.edu

12. url: http://www.wikipedia.com

13. url: http://yosafat.ap.tripod.com

14. Wibowo, F. N. (2005), Pembelajaran Metode Kekakuan Dengan Bantuan Microsoft Excel, Lokakarya Pengajaran Konstruksi Beton dan Mekanika Teknik, 13-14 Juli 2005, Institut Teknologi Sepuluh November, Surabaya. 